\title{
Biographical Transitions From a Midlife Perspective
}

\author{
Pasqualina Perrig-Chiello ${ }^{1,3}$ and Sonja Perren ${ }^{2}$
}

Recent advances in life-span developmental psychology suggest that individual lives can be characterized as a series of interrelated transitions. The question of when and how past transitions have been experienced and how they affect subsequent ageing may be critical to understanding midlife adjustment. The aim of this study is (a) to investigate timing and emotional valence of experienced normative and silent transitions of middle-aged persons, and (b) to discover the impact of past transitions on current well-being and on anticipation of old age. Analysis of interview data from 268 persons suggest a considerable stability in the basic structure of human biography, but also evidence for age group, gender, and personality differences in the subjective perception of the life-course, adjustment and future anticipation in middle age. Emotional valence of puberty and that of personality variables were found to be important predictors of actual psychological well-being and anticipation of old age.

KEY WORDS: middle age; life-span transitions; well-being; personality.

\section{INTRODUCTION}

Midlife as a distinct stage of life is a recent phenomenon resulting from demographic changes in the last century in western society, namely the increase in human longevity and decline in fertility. This might also be one of the reasons why the middle years have been neglected by research (Baruch \& Brooks-Gunn, 1984; Chiriboga, 1997). Upon the entrance of the large baby boom-generation into midlife, there has been an increasing demand for information about this life stage, promoting research on this topic (Wethington, Cooper, \& Holmes, 1997). Recent advances in developmental psychology have shown that ongoing demographic and socio-cultural changes have produced an unprecedented explosion of life-style possibilities for individuals in this age group. What in fact characterizes contemporary midlife is an expanding diversity in roles, relationships, and resources (Moen \& Wethington,

\footnotetext{
${ }^{1}$ Institute of Psychology, University of Berne, Switzerland.

${ }^{2}$ Institute of Psychology, University of Zurich, Switzerland.

${ }^{3}$ To whom correspondence should be addressed at Institute of Psychology, University of Berne Muesmattstr. 45, CH-3000 Berne, Switzerland; e-mail: pasqualina.perrigchiello@psy.unibe.ch.
}

1999). This phenomenon has been referred to by some authors as the age-irrelevant society (Kohli \& Künemund, 2004; Neugarten \& Hagestad, 1976), or as the de-institutionalization of the life course (Held, 1986). The current scientific debate focuses on whether the life course remains standardized or whether this standardization has been eroded in favor of a pluralization of life-styles (Zapf, 1995).

Although it has been suggested that researchers should study pathways rather than stages, the majority of studies on midlife development have concentrated on this single life stage without considering the life history of individuals in terms of experiences and transitions through youth and young adulthood, all of which might shape the quality of present and future existence. Recent advances within a life course framework however have increasingly focused on life pathways, examining developmental transitions and turning points over time (Wheaton \& Gotlib, 1997; Willis \& Reid, 1999). Some authors have emphasized the importance of past experiences and hereto the fact that individuals are the product of their life history as well as of situational demands, opportunities and barriers. Others have criticized the lack of reliable data on this matter (Rutter, 1996). The lack of data is especially true for research on middle age. 
It has been assumed that the way in which individuals cope with the large number of normative and silent transitions in adulthood may strongly influence their way of adapting to the challenges of later life, but little research has been done in this area. Therefore, the question of how middle aged persons report having experienced past transitions and how these specific experiences may affect current well-being and subsequent ageing are important for an accurate understanding of midlife development.

\section{Transitions Within a Life-span Context}

Recent advances in life-span developmental psychology suggest that individual lives can be characterized as a series of interrelated transitions. Transitions involve individual changes and adaptations over the life span and contribute to psychosocial development (Mercer, Nichols, \& Doyle, 1989; Sugarman, 2001). Biographical transitions define points in the life course when roles are transformed, redefined and left behind for new roles. Transitions can be classified-depending on their causal origin-as normative age-graded (such as puberty, climacteric changes), normative history-graded (wars, political and economical crisis) and non-normative (silent) transitions (accidents, losses, illness). The life course perspective assumes that content and timing of transitions are dependent on biological heritage as well as on historical, demographic and socio-structural factors which shape the typical life course of individuals (Elder \& Rockwell, 1979; Elder, 1998). On the one hand, biological maturation obviously helps set the boundaries for the occurrence of normative social transitions, such as readiness for leaving the parental home or having children. On the other hand, the involvement of social regulation in many transitions is evident from the fact that developmental trajectories are also subject to gender differences. For example, women's transitions frequently differ from those of men because of various societal expectations and circumstances. Despite the continuing influence of social regulation, however, transitions today tend to be experienced more and more on a less-public and more-individuated basis: timing of marriage, parenthood, grandparenthood is becoming increasingly idiosyncratic, and in such a way that modern biographies are less and less comparable (Chiriboga, 1989; Kohli, 1986; Kohli \& Künemund, 2004).
Middle age is, like other periods of life, associated with a number of age-normed and silent transitions, but, compared to development in childhood and adolescence, the course of later adulthood is more multifaceted. With advancing age we also observe a significant increase in non-normative transitions, which are known to be associated with higher stress than age-normed ones, owing to the fact that they mostly happen in an unexpected way, making them less predictable (Chiriboga, 1997). Even though there is empirical evidence that transitions are a reality in middle age, little work has been done on individual, group, or gender differences regarding the timing and emotional valence of past transitions and their impact on present and future well-being (Helson, 1997; Keyes \& Ryff, 1999).

\section{Biographical Transitions, Their Emotional Valence and Their Impact on Well-Being and Future Perspectives}

The question regarding the extent to which experienced biographical transitions shape future development and how they might impact on well-being and future perspectives is a crucial and controversial research topic. It has been argued that early transitions can have enduring consequences by affecting subsequent transitions, even after years and decades have passed (with regard to the carrying forward of negative turning point effects, see Clausen, 1991; Vaillant, 1990; Wadsworth, Maclean, Kuh, \& Rodgers, 1990; Wertlieb, 1997; Elder, 1998). Ryff and Heidrich (1997) showed that normative events and transitions were significant predictors of multiple aspects of present and future well-being for different age groups (young, middle-age, and old age). Furthermore, it has been suggested that successful accomplishment of tasks at an earlier stage of development sets the scene for later psychological health (Stewart, Ostrove, \& Helson, 2001). On the basis of secondary analysis of three largescale population survey of adults, Kessler, GillisLight, Magee, Kendler, and Eaves (1997) found a significant relationship between retrospectively reported measures of childhood adversity and several dimensions of adult psychopathology. In particular, the transition to adulthood seems to be age-, event-, and duration-dependent and appears to constrain the shape and time-trajectory of the remaining life course of individuals (Hogan, 1981; Caspi, 1993). Results from a prospective longitudinal study by Verhofstadt-Denève, Schittekatte, and 
Van Leeuwen (2003) indicate a significant relationship between psychosocial experiences during adolescence (e.g. in off-time transitions such as early school-leaving) and degree of well-being in adulthood for both sexes, but especially for women.

The vulnerability and long-reaching impact of this particular transition can be explained by the fact that during this time a crucial and major developmental task has to be resolved, namely the achievement of a secure sense of identity (Erikson, 1959; Marcia, 1980). The successful accomplishment of this task then determines the experience of future life events. Findings from a longitudinal study conducted by Josselson (1987) did indeed show that the configuration of identity in adolescence forms the template for adulthood. As demonstrated by Vandewater and Stewart (1997) in two longitudinal studies, identity development (identity generally thought of as the main accomplishment of adolescence) has important consequences for midlife well-being (see also Marcia, 1980).

Despite the persuasiveness of these studies, others have argued that findings based mainly on retrospective data cannot answer the question as to whether it is objectively experienced transitions per se that have a long-term effect, or whether it is subjective post hoc interpretations that matter more (Rutter, 1996). In our view, this divide is not very helpful for the study of well-being. This is because all autobiographical memories are necessarily subjective, personal reconstructions of the past. It is the currently experienced emotional quality of the memory that accounts for actual well-being-as a reflection of how the event was experienced in emotional terms at the time, as well as how it has been relived and reflected upon since then (Keyes \& Ryff, 1999; Schacter, 1996; Schwarz \& Strack, 1999). Moreover, there is empirical evidence that retrospective reports of biographical events (such as perceived changes of personality) converge in a significant way with the data from prospective longitudinal studies (Costa \& McCrae, 1989; McCrae \& Costa, 1990). From a developmental perspective, several authors have underlined the importance of autobiographical memories for well-being and future perspectives in middle age. Erikson (1959) argued that the ability to really see oneself requires a continuous perspective, both in retrospect and in prospect. It mandates linking the presently understood past and the anticipated future with the present experiences of the individual. In a similar vein, McAdams (1993) has stated that life stories bind together events in time, organizing present reality in terms of connected past and future.

All these studies show, in an impressive manner, the importance of reported past experiences for the organization of present reality and confidence in and preparedness for the future. Furthermore they strongly suggest that recollection and reconstruction of past experiences might be connected with personality variables. In fact, several authors have underlined the important impact of personality (identity certainty, awareness of ageing and generativity) on life transitions and the experience of these (Chiriboga, 1997; Stewart, Ostrove, \& Helson, 2001).

\section{Objectives of this Study}

The aim of this exploratory study is to investigate when and how middle aged persons experienced normative and silent transitions (in childhood, adolescence, adulthood), and when and how they anticipate future ones. Furthermore, we are interested in the predictive power of the retrospective emotional appraisal of past transitions on current physical and psychological well-being and on the anticipation of old age. Special attention is given to age, gender and personality differences. Interview data from two agegroups of middle aged persons (early versus late baby boomers) are presented.

\section{Research Questions}

1. What is the timing of experienced and anticipated transitions? Are there age group and gender differences?

2. How do men and women report having experienced the different transitions in childhood, adolescence, in young and middle adulthood? Are there age group differences? Is emotional valence of transitions associated with their timing?

3. How do anticipation and experience of transitions converge in terms of emotional valence? Are there gender and age group differences?

4. What is the predictive power of the emotional valence of past transitions on current psychological and physical well-being, and anticipation of old age when personality variables are taken into account?

This study is explorative in the sense that, considering the innovative character of these research 
questions and the thin database in this field, it is impossible to formulate specific hypotheses. However, by taking into account the theoretical framework described in the introduction, some general expectations can be set out. Considering to the ongoing social changes, we expect age group and gender differences concerning the timing of transitions that are mainly socially regulated (such as leaving home and getting married). Furthermore, we expect more negative emotional valence for those transitions, which are linked to substantial role changes (such as puberty, having children). And finally, we expect that current well-being and anticipation of old age is predicted by the emotional valence of past transitions as well as by personality variables.

\section{METHOD}

\section{Participants}

The work reported here is part of a large crosssectional study on well-being in middle age with a random sample of 1015 participants belonging to two age groups (younger group: 40-45-years old, late baby boomers born between 1953-1958; older group: 50-55-years old, early baby boomers born between 1943-1948). These two distinct age groups were intentionally chosen in order to allow a concise comparison between persons at the transition into mid-life and those already adapted to it. The sample can be considered as being representative of the healthy, middle aged, urban population in Switzerland (Perrig-Chiello \& Sturzenegger, 2001). In order to enrich and deepen the data of the basic study, in-depth interviews and supplementary questionnaires were planned from the very beginning for use with a subsample. From the 1015 persons, 268 agreed to participate in the second part of the study: 197 women and 71 men belonging to the two agegroups participated in the present interview study: $52 \%$ belonged to the younger age group (mean age $=42.3$ years), $48 \%$ to the older one (mean age $=52.1$ years). Most of the participants were married (70\%), $12 \%$ were single, $16 \%$ divorced and $2 \%$ widowed. Most participants had children: $17 \%$ had one child, $46 \%$ had two, and $22 \%$ had three or more, whilst only $14 \%$ of participants were childless. More than half of the participants had a college or university degree $(35 \%$ resp. $22 \%)$. For the rest, the highest educational degree was mandatory school $(2 \%)$, or a vocational school diploma (40\%). Most participating men were working full-time $(86 \%), 11 \%$ worked part-time, and $3 \%$ were without work. Most of the women worked outside the home part-time (59\%), $19 \%$ outside the home full-time, and $22 \%$ were fulltime home-makers.

\section{Procedure and Instruments}

Participants completed two questionnaires (well-being and personality) and underwent indepth interviews about their biographical transitions (timing and emotional valence; Perrig-Chiello \& Höpflinger, 2001).

\section{Timing and Emotional Valence of Experienced and Anticipated Transitions}

A list of age-normed and frequent non-agenormed transitions was presented and participants had to indicate the age at which the specific transition occurred (timing), as well as the emotional valence of this event (as experienced then; 10-point-scale: $1=$ very negative to $10=$ very positive). The list contained transitions over the whole life-span (from school entry, puberty, first love to anticipation of retirement, and transition to old age). At this point in time, participants had already experienced a series of transitions in the past, were currently undergoing others, and anticipated possible future transitions (see Table I and II).

Anticipation of old age is the score of the emotional valence of the variable "transition to old age (becoming old)" (again, a rating of 1 would mean very negative expectations).

\section{Psychological and Physical Well-Being}

Psychological well-being was assessed by means of a 9-item test that includes the dimensions satisfaction with own past, purpose of life, and mastery (3point scale: $1=I$ do not agree to $3=I$ absolutely agree; $M=2.51, S D=0.32, N=268$ ). This instrument meets all psychometric standards (Cronbach's alpha $=.66$; 3-year stability: $r=.60, p<.001$; for details see Perrig-Chiello, 1997).

Physical well-being was assessed by a single item question on subjective health according to selfevaluation (5-point scale: $1=$ very bad to $5=$ very good; $M=4.13, S D=0.71, N=268)$. 
Table I. Timing of Experienced and Anticipated Transitions by Gender

\begin{tabular}{lcccccc}
\hline \multirow{2}{*}{\multicolumn{1}{c}{ Transitions }} & \multicolumn{2}{c}{$M(S D)$} & & & \\
\cline { 2 - 5 } & \multicolumn{1}{c}{ Men } & Women & $F$ & Breslow & Log rank & $N^{a}$ \\
\hline School entry & $6.7(0.5)$ & $6.7(0.6)$ & 0.07 & - & - & 268 \\
Puberty & $14.4(1.7)$ & $13.4(1.4)$ & $25.65^{* *}$ & - & - & 263 \\
First employment & $20.7(4.6)$ & $19.8(3.2)$ & 2.89 & - & - & 264 \\
First love & $18.0(3.8)$ & $18.4(3.3)$ & 0.43 & - & - & 257 \\
Leaving home & $22.0(3.1)$ & $20.6(3.4)$ & $9.32^{* *}$ & - & - & 264 \\
Getting married & $26.5(4.1)$ & $25.0(4.6)$ & $5.59^{*}$ & - & - & 249 \\
Birth first child & $30.1(4.5)$ & $27.8(4.9)$ & $10.71^{* *}$ & - & - & 225 \\
Birth second child & $32.9(4.7)$ & $29.7(4.2)$ & $20.24^{* *}$ & - & - & 180 \\
Launching first child & $46.7(6.0)$ & $45.7(4.2)$ & & 1.09 & 0.53 & 75 \\
Launching last child & $47.1(7.2)$ & $48.9(4.2)$ & & 3.22 & 3.02 & 24 \\
Grandparenthood & $52.5(2.5)$ & $47.8(4.6)$ & & 1.65 & 0.23 & 17 \\
Climacteric change & $45.7(7.0)$ & $47.0(5.1)$ & & 0.43 & $4.60^{*}$ & 106 \\
Divorce & $37.0(6.8)$ & $36.1(8.2)$ & & 2.88 & 3.41 & 79 \\
Frailty of parents & $44.4(5.4)$ & $41.9(10.8)$ & & 0.52 & 1.26 & 62 \\
Death of mother & $33.6(14.8)$ & $37.3(12.0)$ & & 0.59 & 0.30 & 52 \\
Death of father & $36.0(11.1)$ & $35.6(11.6)$ & & 0.05 & 0.09 & 113 \\
Retirement (anticipated) & $62.1(3.8)$ & $62.7(6.6)$ & 0.41 & - & - & 223 \\
Being old (anticipated) & $72.6(9.9)$ & $75.8(6.8)$ & $7.32^{* *}$ & - & - & 231 \\
\hline
\end{tabular}

${ }^{a}$ Transitions were not experienced by all participants. Thus, the reported sample sizes refer to the number of people who actually had experienced the transition and reported valid scores.

${ }^{*} p<.05 .{ }^{* *} p<.01$.

\section{Personality}

Personality was assessed by means of the NEOFive Factor Inventory (Costa \& McCrae, 1985) (5point-scale: $1=$ strong disapproval to $5=$ strong approval): Neuroticism $(M=2.48, S D=0.64)$, Extraversion $(M=3.37, S D=0.51)$, Openness to experience $(M=3.71, S D=0.45)$, Conscientiousness $(M=3.86, S D=0.43)$, Agreeableness $(M=3.74$, $S D=0.38) ;(N=223)$.

Table II. Emotional Valence of Experienced and Anticipated Transitions by Gender

\begin{tabular}{lccccc}
\hline & \multicolumn{2}{c}{ Experienced } & & \multicolumn{2}{c}{ Anticipated } \\
\cline { 2 - 3 } \multicolumn{1}{c}{ Transitions } & Men $[M(S D)]$ & Woman $[M(S D)]$ & & Men $[M(S D)]$ & Woman $[M(S D)]$ \\
\hline School entry & $6.69(2.56)$ & $7.45(2.44)^{*}$ & & \\
Puberty & $4.99(1.96)$ & $4.71(2.33)$ & & \\
Job entry & $7.32(2.61)$ & $7.75(2.46)$ & & \\
First love & $8.48(2.02)$ & $8.17(2.23)$ & & \\
Leaving home & $7.04(2.40)$ & $7.46(2.74)$ & & \\
Marriage & $8.95(1.31)$ & $7.97(2.36)^{* *}$ & & \\
Birth first child & $9.10(1.33)$ & $7.36(2.81)^{* *}$ & & \\
Birth second child & $9.08(1.66)$ & $7.79(2.44)^{* *}$ & & \\
Launching first child ${ }^{a}$ & $5.09(2.07)$ & $5.88(2.41)$ & & $6.72(2.31)$ & \\
Launching last child & $5.08(1.88)$ & $6.21(2.52)$ & & $6.43(2.30)$ & $5.91(2.47)$ \\
Climacteric change & $5.04(1.67)$ & $5.61(2.05)$ & & $5.00(1.08)$ & $5.63(1.75)$ \\
Divorce & $3.40(2.44)$ & $3.84(3.14)$ & & \\
Grandparenthood & $8.75(1.50)$ & $9.27(2.31)$ & & $8.52(1.50)$ & $8.42(1.85)$ \\
Frailty of parents ${ }^{a}$ & $3.20(1.90)$ & $3.26(2.28)$ & & $4.20(1.75)$ & $3.84(1.73)$ \\
Death of mother & $3.47(2.62)$ & $3.16(2.01)$ & & $3.00(1.65)$ & $3.61(1.96)$ \\
Death of father & $3.00(2.27)$ & $3.03(2.03)$ & & $3.19(1.39)$ & $3.45(1.94)$ \\
Retirement & & & $7.93(1.99)$ & $7.09(2.28)^{* *}$ \\
Being old & & & & $5.68(2.07)$ & $5.47(2.04)$ \\
\hline S & & &
\end{tabular}

${ }^{a}$ Significant experience vs. anticipation effect $(p<.01)$.

${ }^{*} p<.05 .{ }^{* *} p<.01$ (gender differences). 


\section{RESULTS}

\section{Timing of Transitions: Age Group and Gender Differences}

In order to analyze age group and gender differences, we conducted several $2 \times 2$ ANOVAs (Age group $\times$ Gender). As recommended by Willett and Singer (1997), we applied event history techniques to analyze the timing of censored events (some of our observations are right-censored because we stopped observing before the event happened). Event history analysis (also called survival analysis) is used to analyze the occurrence of events over time. The timing of an event within a sample can be visualized and analyzed by means of survival functions (Allison, 1991). We used the Kaplan-Meier method to test the equality of survival distributions for transitions, which we considered to be censored (e.g. grandparenthood). In order to analyze age group and gender differences with regard to the timing of right-censored transitions (launching first child, launching last child, grandparenthood, menopause, divorce, frailty of parents, death of mother, death of father), we report Breslow and Log rank statistics. We used both Breslow and Log rank statistics as they differ in their sensitivity. Breslow is more sensitive than the Log rank test to differences that occur at an earlier time and vice versa (Allison, 1991). For all other transitions (e.g. puberty), we report $F$-values.

Analyses yielded significant gender and age group differences. As can be seen in Table I, and as expected, woman experienced puberty at an earlier age than men. The significant log-rank test concerning timing of climacteric changes indicates a significant gender difference at the extremes of the distribution. Fewer men than women reported the timing of climacteric changes occurring after 50 years. Women experienced leaving home, getting married, birth of first and second child earlier than men, but they anticipated a later onset for being old than men.

Significant age group differences emerged regarding timing of puberty, leaving home, divorce, and anticipation of being old. For all these transitions, the older age group reported a later onset: puberty: $M_{\text {younger }}=13.4(S D=1.5), M_{\text {older }}=$ $14.0(S D=1.6), \quad F(1,261)=9.44, p<.01$; leaving home: $\quad M_{\text {younger }}=20.6(3.7), \quad M_{\text {older }}=21.4(2.9)$, $F(1,262)=3.48, \quad p<.05, \quad$ divorce: $\quad M_{\text {younger }}=$ $33.6(6.8), M_{\text {older }}=39.5(8.0), \quad$ Log rank $=9.99, p<$ .01 , Breslow $=7.73, p<.01$; being old (anticipated):
$M_{\text {younger }}=73.7(8.1), M_{\text {older }}=76.4(7.2), F(1,229)=$ $6.75, p<.05$.

\section{Emotional Valence of Transitions: Age Group and Gender Differences}

In addition to the timing of transitions, participants indicated in retrospect how they had experienced them emotionally at the time (see Fig. 1 and Table II). In order to analyze age group and gender effects, several $2 \times 2$ ANOVAs were carried out (Age group $\times$ Gender). Emotional valence of experienced and anticipated transitions served as dependent variables. The analyses yielded several significant main effects for gender but not for age (no significant interactions).

Women experienced school entry more positively than men, $F(1,264)=4.90, p<.05$, but evaluated their transition to marriage and becoming parents more negatively than men (getting married: $F(1,245)=10.56, p<.01$; birth first child: $F(1,221)=21.05, p<.01$; birth second child: $F(1,176)=12.75, p<.01)$. Lastly, men anticipated retirement more positively than women, $F(1,255)=$ 7.16, $p<.01$ (see also Fig. 1).

To analyze whether timing and emotional valence of transitions are associated, we conducted correlational analyses. The analyses yielded two significant correlations between timing and emotional valence: frailty of parents $(r=.48, p<.01)$ and death of father $(r=.26, p<.01)$. The younger the participants were when they experienced frailty of parents or death of father, the more negative they reported experiencing this transition.

\section{Experienced Versus Anticipated Transitions}

We computed several $2 \times 2 \times 2$ ANOVAs in order to measure the convergence between experienced and anticipated transitions (Anticipation/experience $\times$ Age group $\times$ Gender $)$. Emotional valence of transitions in middle adulthood served as dependent variables (launching first child, launching last child, grandparenthood, climacteric changes, frailty of parents, death of mother, death of father). The analyses yielded two main effects of anticipation, but no other significant effects. In Table II means of emotional valence by gender are displayed.

A significant anticipation main effect emerged for frailty of parents, $F(1,229)=7.68, p<.01$ : frailty of parents was more negatively experienced than anticipated. In addition, the analyses 

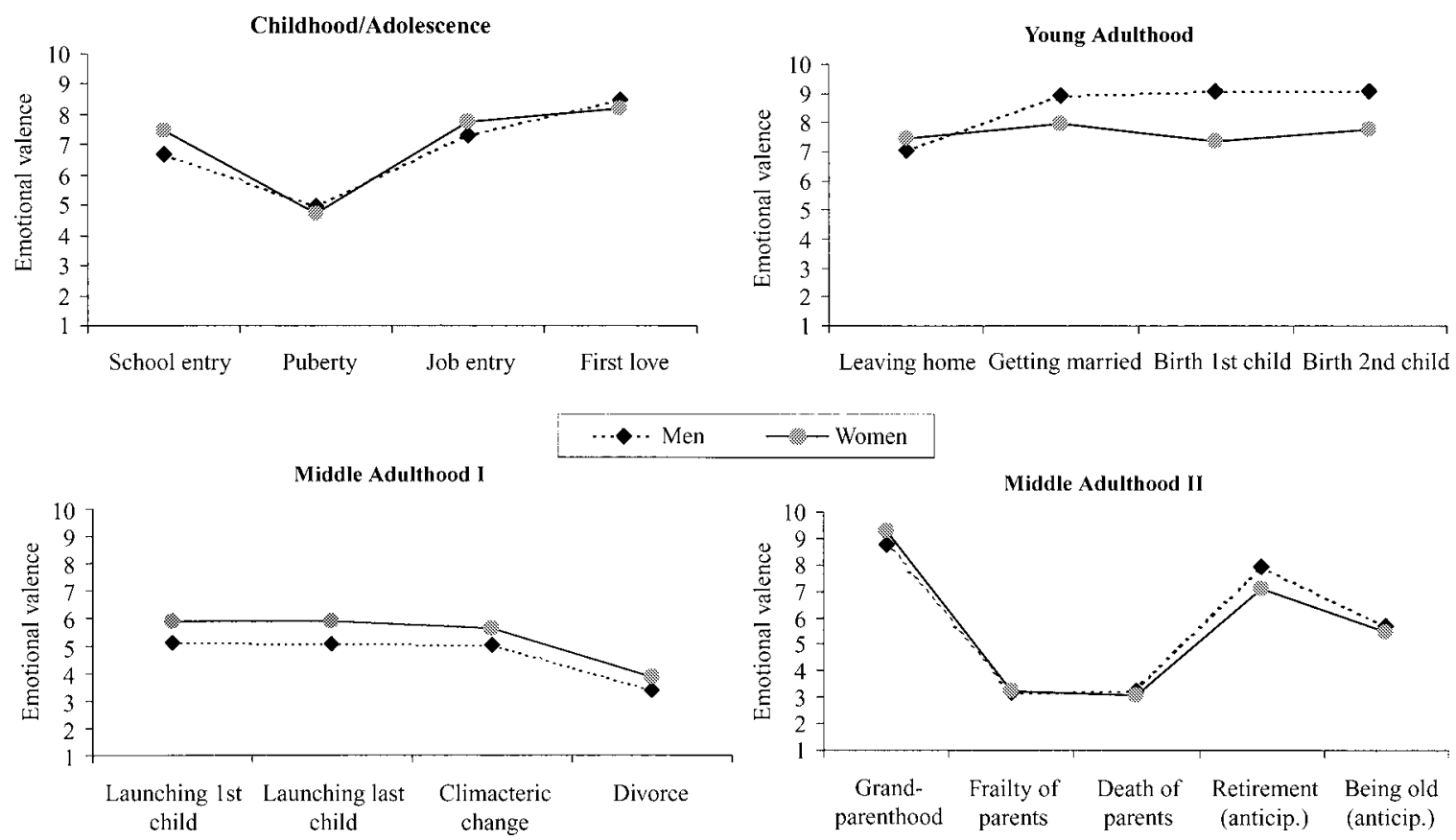

Fig. 1. Emotional valence of experienced transitions over the life course.

yielded a significant main effect of anticipation regarding the transition involved in launching the first child, $F(1,217)=9.04, p<.01$. Launching the first child was more negatively experienced than anticipated. Moreover, the analyses yielded a near significant Gender $\times$ Anticipation interaction effect, $\mathrm{G} \times \mathrm{A}: F(1,217)=3.47$, $p=.06$, with the difference between anticipation and experience being much greater for men than women.

\section{Predictive Power of Past Transitions and Personality on Well-Being and Anticipation of Old Age}

In order to calculate associations between personality and emotional valence of transitions, parametric correlation analyses (Pearson) were conducted. Some significant correlations emerged (see Table III). Neuroticism correlated negatively with emotional valence of experienced puberty, job entry, getting married, and birth of children; extraversion correlated positively with the emotional valence associated with puberty, getting married, and divorce; openness was negatively correlated with emotional experience of getting married; conscientiousness correlated positively with puberty and job entry; agreeableness did not correlate significantly with any of the emotional valences of the transitions.

Regression analyses were performed in order to evaluate the predictive power of emotional valence of experienced transitions, together with personality variables, on psychological and physical well-being and anticipation of being old. Age group and gender, emotional valence of transitions from childhood to young adulthood (school entry, puberty, first love, job entry, marriage, birth), as well as personality, served as independent variables. We performed hierarchical regression analyses with age group and gender entered as block 1, emotional valence of transitions as block 2 , and personality variables as block 3. Anticipation of being old (emotional valence), psychological well-being, and physical well-being served as dependent variables. Since the sample consists of two age cohorts, age is not evenly distributed across the age range. Thus, we used age rather as dichotomous than as a continuous variable in the statistical analyses.

Analyses revealed that anticipation of the transition to old age (becoming old) was best predicted by the emotional valence of puberty (even when controlling for personality variables), and also by neuroticism: the more negatively puberty was said to have been experienced, and the higher the 
Table III. Correlations (Pearson) Between Emotional Valence of Transitions and Personality Variables

\begin{tabular}{lccccr}
\hline $\begin{array}{c}\text { Transitions } \\
\text { (emotional valence) }\end{array}$ & Neuroticism & Extraversion & Openness & Conscientiousness & Agreeableness \\
\hline School entry & .01 & -.03 & .12 & -.02 & -.08 \\
Puberty & $-.17^{*}$ & $.19^{*}$ & -.04 & $.20^{* *}$ & .02 \\
Job entry & $-.19^{* *}$ & .12 & -.08 & $.25^{* *}$ & .02 \\
First love & -.01 & .01 & -.00 & .03 & -.08 \\
Leaving home & -.09 & .07 & -.01 & .09 & .05 \\
Marriage & $-.20^{* *}$ & $.17^{*}$ & $-.19^{*}$ & .03 & .03 \\
Birth first child & $-.16^{*}$ & .13 & -.01 & .12 & -.04 \\
Birth second child & -.12 & .08 & -.06 & .01 & .06 \\
Launching first child & -.07 & .04 & -.05 & -.06 & .14 \\
Launching last child & -.25 & .16 & -.16 & -.17 & .04 \\
Climacteric change & -.08 & -.04 & -.01 & -.15 & -.06 \\
Divorce & -.23 & $.28^{*}$ & .16 & .07 & -.00 \\
Grandparenthood & .41 & -.46 & -.29 & .32 & -.09 \\
Frailty of parents & .07 & -.08 & .03 & .14 & .07 \\
Death of mother & -.15 & .14 & .09 & -.23 & -.00 \\
Death of father & .05 & -.01 & .14 & .08 & -.00 \\
* $p<.05 . * * p<01$. & & & & &
\end{tabular}

neuroticism-score, the more negatively the transition to old age was anticipated. Emotional valence of puberty was also a significant predictor of current psychological well-being, but only before entering personality variables. Psychological well-being was best predicted by neuroticism (by entering these two variables the predictive power of past transitions disappeared): low scores for neuroticism and high scores for conscientiousness were associated with high psychological well-being. As can be seen in Table IV a major change regarding overall model fit was observed when we entered the personality variables that predicted psychological well-being. Finally, neuroticism predicted physical well-being, and did not seem not be related to the recollected experience of past transitions (for details see Table IV).

\section{DISCUSSION}

The aim of this research was to find out the timing and emotional appraisal of retrospective and prospective transitions of middle aged persons, and how these relate to current physical and psychological well-being, and the anticipation of old age. Special attention was given to age, gender and personality differences.

Despite the fact that it has been postulated in the literature that the timing of transitions is becoming more and more idiosyncratic, the biographies emerging from our sample suggest that a broadly similar structure, befitting a rather standardized series of transitions spanning right across childhood, adolescence and young adulthood, can still be found. At the same time, however, certain age group and gender differences were found, in particular for events occurring in the middle years. Here, a greater variation in the nature and timing of experienced transitions was indeed apparent. The detected age and gender differences in timing of transitions may underline their biological regulation but still with considerable societal input. Women report experiencing the onset of puberty significantly earlier then men. This is even true for the older age group, who report having experienced the onset of puberty later than the younger group. Even though the two age groups are only 10 years apart, this fact reflects the secular acceleration of puberty. Climacteric changes - a further age-normed transition-are reported earlier by men ( $M=45.7$ years) than women ( $M=47$ years). Likewise, we have to take into account the large variance of the indicated timing, especially for men $(S D=7$ years; women: $S D=$ 5.1 years). These results may reflect uncertainty towards the phenomenon of male andropause, which has received increasing media interest in the last decade, but which still remains unclear (Webb, 1985; Diamond, 2000). Another significant gender difference that was reported points to the endurance of social regulation of transitions: the study showed that women in this specific cohort still leave home, marry and bear children at earlier ages than men. This ties in with the fact that, women (even in Western culture) are still expected to be younger than their partners and the fathers of their children; furthermore, 
Table IV. Summary of Hierarchical Regression Analysis for Variables Predicting Anticipation "Being Old," Psychological and Physical Well-Being

\begin{tabular}{clccc}
\hline \multirow{3}{*}{ Model } & \multicolumn{1}{c}{$\begin{array}{c}\text { Independent } \\
\text { variables }\end{array}$} & $\begin{array}{c}\text { Anticipation } \\
\text { "being old" }\end{array}$ & $\begin{array}{c}\text { Psychological } \\
\text { well-being }\end{array}$ & $\begin{array}{c}\text { Physical } \\
\text { well-being }\end{array}$ \\
\hline Model I & Gender & -.06 & $-.12^{* *}$ & -.11 \\
& Age group & .08 & .09 & .02 \\
& Gender & -.01 & -.15 & -.07 \\
& Age group & .07 & .08 & .01 \\
& School entry (EV) & -.00 & -.08 & .00 \\
& Puberty (EV) & $.19^{*}$ & $.18^{*}$ & .02 \\
& First love (EV) & .13 & .02 & -.04 \\
Leaving home (EV) & .06 & .01 & -.05 \\
& Job entry (EV) & .15 & .15 & .04 \\
& Getting married (EV) & .11 & .12 & .09 \\
& Birth (EV) & -.02 & -.02 & .07 \\
Gender & .05 & .01 & .03 \\
& Age group & .05 & .03 & -.02 \\
School entry (EV) & -.02 & -.06 & .03 \\
Puberty (EV) & $.18^{*}$ & .08 & -.05 \\
& First love (EV) & .13 & .05 & -.02 \\
& Leaving home (EV) & .05 & -.03 & -.07 \\
& Job entry (EV) & .13 & .02 & -.04 \\
Getting married (EV) & .11 & .09 & .05 \\
Birth (EV) & -.02 & -.05 & .05 \\
& Neuroticism & $-.19^{*}$ & $-.53^{* *}$ & $-.35^{* *}$ \\
& Extraversion & .01 & .01 & .05 \\
Openness & .03 & -.05 & -.07 \\
& Conscientiousness & -.01 & $.18^{*}$ & .05 \\
Agreeableness & -.10 & -.02 & -.03 \\
& Model I & $R^{2}=.01$ & $R^{2}=.05$ & $R^{2}=.01$ \\
Model II & $R^{2}=.13$ & $R^{2}=.13$ & $R^{2}=.03$ \\
& Model III & $R^{2}=.16$ & $R^{2}=.42$ & $R^{2}=.15$ \\
\hline
\end{tabular}

${ }^{*} p<.05 .{ }^{* *} p<.01$.

they are expected to be autonomous and able to run their own household at an earlier age than men (de Vries \& Watt, 1996).

The younger group divorced on average at an earlier point in time than the older group. This means that the persons of the younger age group must have had a lower threshold for getting divorced than the older one-a tendency that can be explained by the rapid sociocultural changes of the last decades. The younger age group (who went to school in the early 60s, and experienced puberty around 1968) seemed to be striving for more personal freedom, more openness, and less commitment to traditional norms, than the older age group (born during and directly after the World War II and who had their schooling in the 50s and puberty before 1968).

Anticipation of being old is a rather complex variable, possibly reflecting anxieties and prejudice held by our society toward old age. There is evidence, for example, that people of all ages hold negative stereotypes about ageing, which can influence their projections of themselves into the future (Butler,
1969; 1990; Hummert, 1999; Slotterback, 1996). This form of ageism, which serve to reinforce discriminatory cultural practice, may be one major reason why the prospect of getting older is associated with a rather negative emotional valence in the data we collected. In this context, the fact that the older age group in our study anticipated reaching old age at a later time in life that did their younger counterparts, can be seen as their attempt at expanding the boundary as soon as soon as they see themselves approaching it-a well-known phenomenon in gerontology (Seccombe \& Ishii-Kuntz, 1991). The tendency was more pronounced in women than in men-possibly because women are more concerned about ageing, and more often subjected to ageism (Gee \& Kimball, 1987; Nett, 1982).

Concerning the emotional valence of experienced transitions, clear overall patterns can be observed in our data, despite some fairly substantial individual and group differences. In contrast to childhood and adolescence, most midlife transitions are of rather more negative emotional valence. This finding 
appears to support the idea of an increasingly negative win-loss-balance operating with advancing age (see Baltes, 1987). It is of interest, but perhaps not very surprising (see Erikson's psychosocial developmental stages model) that, from the perspective of our midlife sample, events with the most positive emotional valence do not concern transitions involving personal growth, or love and romance, but rather individuals' situation vis-à-vis their offspring. In fact, the transition to becoming grandparents has the most positive emotional valence as a whole, followed by the transition of becoming parents. Our finding converges with the phenomenon described by Seltzer and Ryff (1996) that the majority of parents in midlife report ever-improving relationships with their children, as both parents and children grow older. Rossi and Rossi (1990) suggest that intimacy between parents and adult children usually increases over the adult years, and, presumably, such increments have positive consequences for parents' wellbeing. Grandparenthood is frequently an eagerly anticipated role in middle years, and is deemed to be a central element of generativity, which can contribute towards giving a sense of being important for the younger generations (Cherlin \& Furstenberg, 1986; McAdams, Hart, \& Maruna, 1998; Smith, 1991). Several surveys have shown, in impressive manner, the emotional, social, and economic importance of the grandparent-generation for their offspring (AttiasDonfut, 1995; Kohli, Künemund, Motel, \& Szydlik, 1998). Considering the multiple importance which the oldest generation still plays for their adult children, and the obligations which the latter may feel and have towards them, it is understandable that acknowledging with the frailty and death of one's own parents is the transition with the most negative emotional valence for persons in middle age.

Another transition associated with highly negative emotional valence, and affecting about one third of our sample, is that of divorce. This result confirms Chiriboga's claim that unexpected transitions, such as marital separation, lead to more heightened exposure on multiple stress dimensions than the more predictable transitions (Chiriboga, 1997; Wrosch \& Freund, 2001).

Although the literature reports considerable gender differences concerning the amount of remembered relational and romance life events (women reporting significantly more events then men), better recollection does not seem to be associated with more positive memories: in our sample, women evaluated their transition to marriage and parenthood more negatively than men. It seems that for them, these transitions represent more radical changes with more extensive effects on their life trajectories. From the perspective of middle-aged women, becoming a wife and mother seems still to imply a much more substantial role change than for men. In contrast, men have not had to change their career plans, or their role in the labor force upon reaching these transitions-factors that are known to be important sources of purposive activity, independence, social relations, and self-respect (Moen \& Wethington, 1999).

We know from the literature, and from everyday life, that launching children into adulthood is an especially important midlife event in our society. Although much has been made of this as a negative time (empty nest syndrome), some researchers have shown that there is much less distress than has been assumed previously (Antonucci \& Akiyama, 1997; Perrig-Chiello \& Sturzenegger, 2001). Possible explanations for the contradictory reports are cohort effects and a neglect of individual and group differences. Our data underline this assumption in the way that, in our sample, men and women experience the challenge of launching children in different ways. Even though men and women anticipate this transition as rather neutral to positive, the experience itself is accordingly to our study, significantly more negative in men than in women. This result may surprise, as the empty-nest phenomenon has traditionally been attributed to women. The most obvious explanation, however, is that women find it easier to cope with the transition because they no longer define themselves totally through their role as wife and mother-the majority of them being employed outside the home. Furthermore, it is known that mothers still keep in contact with their sons and daughters, which is far less the case for fathers. Another less obvious explanation falls on shifting roles by fathers in our society. There is, for example, empirical evidence that the success of the role of father approaches its zenith in midlife (Nydegger \& Mitteness, 1996). Fathers at this time have established adult relations with their children. Their influence and importance to their children appears to be at a peak; and children are reported to feel closer to their fathers now than ever before. In the same vein, Rossi and Rossi (1990) have hypothesized that the experience of fatherhood may encourage the flowing of tender, nurturing qualities in men, whose prior socialization, unlike that of women, had not encouraged such qualities. 
In general, we observed in our study a tendency to anticipate potentially negative transitions less negatively than they are actually experienced. This optimistic anticipation of one's own biography seems to be a self-protective mechanism crucial for adaptive and sound development. It seems reasonable that individuals charged with the task of writing their own future would choose to do so in ways that they would find appealing and supportive of a positive self-evaluation (de Vries \& Watt, 1996; Tesser \& Campbell, 1982).

Finally, our results suggest that the emotional valence of passed transitions per se has only a restricted importance for predicting well-being and future perspectives in middle age. Out of all reported transitions only puberty was found to be a significant predictor, and with personality variables-especially neuroticism-shown to play a dominant role. These observations underline, on the one hand, the importance of the transition to adulthood for future development, and, on the other hand, the strong impact of personality on life-long adaptation. One explanation for the predictive power of the transition to adulthood is that puberty can be seen as an anchor point for identity formation, and that memories from this period help us define who we are in later life (Fitzgerald, 1988; Fitzgerald \& ShifleyGrove, 1999; Rybash, 1999). According to McCrae and Costa (1990), identity refers to those aspects of the self that are essential to one's self definition, and which are a salient part of one's personality. Indeed, as noted above, our results indicate that current wellbeing and the anticipation of future development in middle age are also strongly related to personality factors, especially to neuroticism. McCrae and Costa (1990) see neuroticism as the aspect of personality most relevant to life-long adjustment, with those high on this dimension being more likely to show evidence of maladjustment at all ages. In fact, neuroticism appears to be an enduring and consequential disposition, the antecedents of which can be identified early in life. There is empirical evidence that a person's coping style and adaptive devices in early adolescence are important in determining their future life course (Elder \& Crosnoe, 2002; Moen, 1997; Vaillant, 1977).

In sum, this study provides evidence of considerable stability in the basic structure in human biography, but also evidence of age group, gender, and personality differences in the subjective perception of the life-course, adjustments and future anticipations in middle age. There are some limitations that should be mentioned: (a) the restricted representativity of our sample and (b) the cross-sectional retrospective design. However, considering the poor data base on the studied topic, these limitations have to been relativized, and we think that our approach is a useful first step. In line with Stewart et al. (2001), one cannot expect that retrospective and prospective reports describe the process of ageing in the same way as longitudinal data would. Prospective studies would certainly be a welcome addition to these findings, but one should not neglect the fact that retrospective accounts can inform us reliably about the present subjective experience of individuals' lifespan development. This in itself is worthwhile.

\section{ACKNOWLEDGMENT}

We thank the Swiss National Science Foundation for supporting the study (Nr. 5004-058457).

\section{REFERENCES}

Allison, P. D. (1991). Event history analysis: Regression for longitudinal event data. Newbury Park: Sage.

Antonucci, T., \& Akiyama, H. (1997). Concern with others at midlife: Care, comfort, or compromise? In M. E. Lachman \& J. B. James (Eds.), Multiple paths of midlife development (pp. 147-169). Chicago, IL: University of Chicago Press.

Attias-Donfut, C. (1995). Les solidarités entre générations. Paris: Ed. Nathan.

Baltes, P. B. (1987). Theoretical propositions of life-span developmental psychology. Developmental Psychology, 23, 611-626.

Baruch, G., \& Brooks-Gunn, J. (1984). Women at midlife. New York: Plenum.

Butler, R. N. (1969). Age-ism: Another form of bigotry. The Gerontologist, 9, 243-246.

Butler, R. N. (1990). A disease called ageism. Journal of the American Geriatrics Society, 38, 178-180.

Caspi, A. (1993). Why maladaptive behaviors persists: Sources of continuity and change across the life course. In D. C. Funder, R. D. Parke, C. Tomlinson-Keasey, \& K. Widaman (Eds.), Studying lives through time: Personality and development (pp. 343-376). Washington, DC: American Psychological Association.

Cherlin, A. J., \& Furstenberg, F. F. (1986). The new American grandparent: A place in the family, a life apart. New York: Basic Books.

Chiriboga, D. A. (1989). Mental health at the midpoint: Crisis, challenge, or relief? In S. Hunter \& M. Sundel (Eds.), Midlife myths: Issues, findings, and practice implications (pp. 116144). Newbury Park, CA: Sage.

Chiriboga, D. A. (1997). Crisis, challenge, and stability in middle years. In M. E. Lachman \& J. B. James (Eds.), Multiple paths of midlife development (pp. 293-322). Chicago, IL: University of Chicago Press.

Clausen, J. S. (1991). Adolescent competence and the shaping of the life course. American Journal of Sociology, 96, 805-842.

Costa, P. T., \& McCrae, R. R. (1985). Manual for the NEO Personality Inventory. Odessa, FL: Psychological Assessment Resources, Inc. 
Costa, P. T., \& McCrae, R. R. (1989). Personality continuity and the changes of adult life. In M. Storand \& G. R. Vandenbos (Eds.), The adult years: Continuity and change (pp. 45-77). Washington, DC: American Psychological Association.

de Vries, B., \& Watt, D. (1996). A lifetime of events: Age and gender variations in the life story. International Journal of Aging and Human Development, 42, 81-102.

Diamond, J. (2000). Surviving male menopause. Napperville: Sourcebook.

Elder, G. H. (1998). The life course as developmental theory. Child Development, 69, 1-12.

Elder, G. H., \& Crosnoe, R. (2002). The influence of early behavior patterns on later life. In L. Pulkkinen \& A. Caspi (Eds.), Paths to successful development (pp. 157-177). Cambridge, UK: Cambridge University Press.

Elder, G. H., \& Rockwell, R. C. (1979). The life course and human development: An ecological perspective. International Journal of Behavioural Development, 2, 1-21.

Erikson, E. H. (1959). Identity and the life cycle. New York: International University Press.

Fitzgerald, J. M. (1988). Vivid memories and the reminiscence phenomenon: The role of a self narrative. Human Development, 31, 261-273.

Fitzgerald, J. M., \& Shifley-Grove, S. S. (1999). Memory and affect: Autobiographical memory distribution and availability in normal and recently detoxified alcoholics. Journal of Adult Development, 6, 11-19.

Gee, E. M., \& Kimball, M. M. (1987). Women and aging. Toronto: Butterworths.

Held, T. (1986). Institutionalization and deinstitutionalization of the life course. Human Development, 29, 157-162.

Helson, R. (1997). The self in middle age. In M. E. Lachman \& J. B. James (Eds.), Multiple paths of midlife development (pp. 21-45). Chicago: University of Chicago Press.

Hogan, D. P. (1981). Transitions and social change: The early lives of American men. New York: Academic Press.

Hummert, M. L. (1999). A social cognitive perspective on age stereotypes. In T. M. Hess \& F. Blanchard-Fields (Eds.), Social cognition and aging (pp. 175-196). San Diego: Academic Press.

Josselson, R. (1987). Finding herself: Pathways to identity development in women. San Francisco: Jossey-Bass.

Kessler, R. C., Gillis-Light, J., Magee, W. J., Kendler, K. S., \& Eaves, L. J. (1997). Childhood adversity and adult psychopathology. In I. H. Gotlib \& B. Wheaton, B. (Eds.), Stress and adversity over the life course (pp. 29-49). Cambridge, UK: Cambridge University Press.

Keyes, C. L. M., \& Ryff, C. D. (1999). Psychological well-being in midlife. In S. L. Willis \& J. D. Reid (Eds.), Life in the Middle. Psychological and social development in middle age (pp. 161182). San Diego: Academic Press.

Kohli, M. (1986). Social organization and subjective construction of the life course. In A. B. Sorensen, F. E. Weinert, \& L. R. Sherrod (Eds.), Human development and the life course: Multidisciplinary perspectives (pp. 272-292). Hillsdale, NJ: Erlbaum.

Kohli, M., \& Künemund, H. (2004). Die Grenzen des AltersStrukturen und Bedeutungen. In P. Perrig-Chiello \& F. Höpflinger (Eds.), Jenseits des Zenits. Frauen und Männer in der zweiten Lebenshälfte (pp. 37-61). Bern: Haupt.

Kohli, M., Künemund, H., Motel, A., \& Szydlik, M. (1998). Generationenbeziehungen. In M. Kohli \& H. Künemund (Eds.), Die zweite Lebenshälfte-gesellschaftliche Lage und Partizipation. Ergebnisse des Alters-Survey (Bd. 1, pp. 189-230). Berlin: Forschungsgruppe Altern und Lebenslauf (FALL) der Freien Universität Berlin.

Marcia, J. (1980). Identity in adolescence. In J. Adelson (Ed.), Handbook of adolescence (pp. 159-187). New York: Wiley.
McCrae, R. R., \& Costa, P. T. (1990). Personality in adulthood. New York: Guilford Press.

McAdams, D. P., Hart, H. M., \& Maruna, S. (1998). The anatomy of generativity. In D. P. McAdams \& E. de St. Aubin (Eds.), Generativity and adult development. Washington, DC: American Psychological Association.

McAdams, D. P. (1993). The stories we live by: Personal myths and the making of the self. New York: Morrow.

Mercer, R. T., Nichols, E. G., \& Doyle, G. C. (1989). Transitions in a woman's life. Major life events in developmental context. New York: Springer.

Moen, P., \& Wethington, E. (1999). Midlife Development in a Life Course Context. In S. L. Willis \& J. D. Reid (Eds.), Life in the middle. Psychological and social development in middle age (pp. 3-25). San Diego: Academic Press.

Moen, P. (1997). Women's roles and resilience: Trajectories of advantage or turning points? In I. H. Gotlib \& B. Wheaton (Eds.), Stress and adversity over the life course (pp. 133-159). Cambridge, UK: Cambridge University Press.

Neugarten, B. N., \& Hagestad, G. O. (1976). Age and the life course. In R. Binstock \& E. Shanas (Eds.), Handbook of aging and social sciences. New York: Van Nostrand Reinhold.

Nett, E. (1982). A call for feminist correctives to research on elders. Resources for Feminist Research, 11, 225-226.

Nydegger, C. N., \& Mitteness, L. S. (1996). Midlife: The prime of fathers. In C. D. Ryff \& M. M. Seltzer (Eds.), The parental experience in midlife (pp. 533-559). Chicago: University of Chicago Press.

Perrig-Chiello, P. (1997). Ressourcen des Wohlbefindens im Alter. Weinheim: Juventa.

Perrig-Chiello, P., \& Sturzenegger, M. (2001). Social relations and filial maturity in middle-aged adults: Contextual conditions and psychological determinants. Zeitschrift für Gerontologie und Geriatrie, Special Issue "Ageing in Europe," 34, 21-27.

Perrig-Chiello, P., \& Höpflinger, F. (2001). Zwischen den Generationen-Frauen und Männer im mittleren Lebensalter. Zürich: Seismo-Verlag.

Rossi, A. S., \& Rossi, P. H. (1990). Of human bonding: Parentchild relations across the life course. New York: Aldine de Gruyter.

Rutter, M. (1996). Transitions and turning points in developmental psychopathology: As applied to the age span between childhood and mid-adulthood. International Journal of Behavioral Development, 19, 603-626.

Rybash, J. M. (1999). Aging and autobiographical memory: The long and bumpy road. Journal of Adult Development, 6, 1-10.

Ryff, C. D., \& Heidrich, S. M. (1997). Experience and wellbeing: Explorations on domains of life and how they matter. International Journal of Behavioral Development, 20, 193206.

Schacter, D. L. (1996). Searching for memory. The brain, the mind, and the past. New York: Basic Books.

Schwarz, N., \& Strack, F. (1999). Reports of subjective well-being: Judgmental processes and their methodological implications. In D. Kahneman, E. Diener, \& N. Schwarz (Eds.), Well-being. The foundations of hedonistic psychology (pp. 61-85). New York: Russell Sage.

Seccombe, K., \& Ishii-Kuntz, M. (1991). Perceptions of problems associated with aging: Comparisons across four elder age cohorts. The Gerontologist, 31, 527-533.

Seltzer, M. M., \& Ryff, C. D. (1996). The parental experience in midlife: Past, present, and future. In C. D. Ryff \& M. M. Seltzer (Eds.), The parental experience in midlife (pp. 641663). Chicago: University of Chicago Press.

Slotterback, C. (1996). Projections of aging: Impact of generational differences and the aging process on perceptions of adults. Psychology and Aging, 11, 552-559.

Smith, P. K. (1991). The psychology of grandparenthood. An international perspective. London: Routledge. 
Stewart, A. J., Ostrove, J. M., \& Helson, R. (2001). Middle aging in women: Patterns of personality change from the 30 s to the 50s. Journal of Adult Development, 8, 23-37.

Sugarman, L. (2001). Life-span development. Frameworks, accounts and strategies (2nd ed.). East Sussex: Psychology Press.

Tesser, A., \& Campbell, J. (1982). Self-evaluation maintenance and the perception of friends and strangers, Journal of Personality, 50, 261-279.

Vaillant, G. E. (1977). Adaptation to life. Boston: Little, Brown.

Vaillant, G. E. (1990). Avoiding negative life outcomes: Evidence from a forty-five year study. In P. B. Baltes \& M. M. Baltes (Eds.), Successful aging: Perspectives from the behavioural sciences (pp. 323-358). New York: Cambridge University Press.

Vandewater, E. A., \& Stewart, A. J. (1997). Women's career commitment patterns and personality development. In M. E. Lachman \& J. B. James (Eds.), Multiple paths of midlife development (pp. 375-411). Chicago: University of Chicago Press.

Verhofstadt-Denève, L., Schittekatte, M. \& Van Leeuwen, K. (2003). Gender differences in developmental pathways on self-evaluation from adolescence into adulthood: The Flanders Longitudinal Study. International Journal of Adolescent Medicine and Health, 15(2),139-152.

Wadsworth, M. E. J., Maclean, M., Kuh, D., \& Rodgers, B. (1990). Children of divorced and separated parents. Family Practice, 7, 104-109.

Webb, C. (1985). Sexuality, nursing, and health. New York: John Wiley.
Wertlieb, D. (1997). Children whose parents divorce: Life trajectories and turning points. In I. H. Gotlib \& B. Wheaton (Eds.), Stress and adversity of the life course (pp. 179-197). Cambridge, IL: Cambridge University Press.

Wethington, E., Cooper, H., \& Holmes, C. S. (1997). Turning points in midlife. In I. H. Gotlib \& B. Wheaton (Eds.), Stress and adversity of the life course (pp. 215-231). Cambridge: Cambridge University Press.

Wheaton, B., \& Gotlib, I. H. (1997). Trajectories and turning points over the life course: Concepts and themes. In I. H. Gotlib \& B. Wheaton (Eds.), Stress and adversity over the life course (pp. 1-29). Cambridge, UK: Cambridge University Press.

Willett, J. B., \& Singer, J. D. (1997). Using discrete-time survival analysis to study event occurrences across the life course. In I. H. Gotlib \& B. Wheaton (Eds.), Stress and adversity of the life course (pp. 273-294). Cambridge, UK: Cambridge University Press.

Willis, S. L., \& Reid, J. D. (1999). Life in the middle. Psychological and social development in middle age. San Diego: Academic Press.

Wrosch, C., \& Freund, A. M. (2001). Self-regulation of normative and non-normative developmental challenges. Human Development, 44, 264-283.

Zapf, W. (1995). Entwicklung und Sozialstruktur moderner Gesellschaften. In H. Korte \& B. Schäfers (Eds.), Einführung in die Hauptbegriffe der Soziologie (pp. 181-191). Opladen: Leske \& Budrich. 